\title{
DIALOGUE:
}

\section{TIME TO ELIMINATE THE PENNY?}

In this issue of the Journal we introduce a new occasional feature: Dialogue. The purpose of this feature is to highlight and encourage debate and discussion on economic issues. Candidates for inclusion in this feature are submissions that extend, significantly modify, or contradict the findings of an article previously published in the Eastern Economic Journal. Any such submission undergoes the normal review process, with the exception that one of the referees is the author of the $E E J$ article addressed by the new paper. If the paper is ultimately accepted for publication, that referee is invited to write a short comment on the final draft which will then be published along with it. We encourage our readers to submit papers that build on work previously published in this Journal and would thus be considered for future rounds of Dialogue.

In "Time to Eliminate the Penny from the U.S. Coinage System: New Evidence," author Robert Whaples addresses the contention advanced in Raymond E. Lombra's 2001 EEJ article, "Eliminating the Penny from the U.S. Coinage System: An Economic Analysis" [Fall 2001, 433-42], that removing the penny from circulation would have several adverse effects. Whaples comes to the opposite conclusion, namely that it is time for the U.S. Mint to cease producing pennies. Lombra responds to this article with his comment, "Pennies, Pricing, and Rounding: Is all the Relevant Analysis In?" Their debate has generated a great deal of interest even in advance of its formal publication, with Whaples and Lombra both citing evidence from their papers in the Wall Street Journal's online "Econoblog" feature on November 17, 2006. We are pleased that the $E E_{J}$ has provided a forum for discussion of this lively and timely topic.

Joyce P. Jacobsen

Gilbert L. Skillman

Eastern Economic Journal, Vol. 33, No. 1, Winter 2007 